\title{
Implementation of Fuzzy Logic Controller in WECS to Achieve Unity Power Factor
}

\author{
Dr. Hari Krishnan $\mathrm{P}^{1}$ \\ Assistant Professor \\ Department of Electrical and Electronics Engineering \\ Anna University, Regional Campus- Coimbatore \\ Tamil Nadu, India
}

\author{
Ponmathy $\mathrm{M}^{2}$ \\ PG Scholar \\ Department of Electrical and Electronics Engineering \\ Anna University, Regional Campus- Coimbatore \\ Tamil Nadu, India
}

\begin{abstract}
This thesis proposes unity power factor achievement using Vienna rectifier in wind energy conversion system (WECS). Among various topologies, Vienna rectifier is considered for the proposed topology. In proposed system the Vienna rectifier is interfaced with wind turbine system in order to drive permanent magnet synchronous generator. The fuzzy Logic controller and Hysteresis Current Control are used to reduce the current harmonics and also maintain constant voltage to the grid. By comparing the result of proposed topology with the conventional topology, it is observed that Vienna rectifier is superior to six switch controlled rectifier. The wind turbine generator- electronic power converter is modeled in MATLAB/ SIMULINK and the results of the simulation on test the system's efficacy in providing adequate efficiency for the condition discussed.
\end{abstract}

Index terms- Hysteresis current control, permanent magnet synchronous generator, pulse width modulation, Vienna rectifier.

\section{INTRODUCTION}

Wind power is among the renewables which are attracting plenty in recent years. Wind, a ubiquitous kind of energy has been utilized by people for quite two thousand years. A WECS converts mechanical energy from wind to usable kind of power. Wind energy may be converted to mechanical power by windmills to grind corn or transfer water from low-lying districts since ancient times. The primary WECS was inbuilt Persia. Wind energy was converted to power so the energy may be managed more easily. Wind generation ranks second in power consumption among all the renewable energy sources. A turbine, or also called a wind energy converter, could be a system that transforms the mechanical energy of the wind into electrical power.

The wind could be a source of great stochastic energy. There's also a big interdependence between the wind turbine's aerodynamic characteristics, the rotor speed of the generator, and therefore the amount of power that may be extracted from the wind. Therefore, an impression method that can allow the most power to be extracted from the system under all possible operating conditions becomes important. As offshore wind speeds average around 90 per cent over land speeds, offshore resources will contribute significantly more energy than land-stationed turbines. Wind generation systems may be used either as stand-alone or as grid-connected systems. Here, build for a stand-alone energy conversion system (WECS) using the Front-end converter (Vienna rectifier).To attain unity power think about the forepart wind energy conversion system rectifier.

\section{A. Vienna rectifier}

\section{SYSTEM DESCRIPTION}

The VIENNA rectifier and most of this research focus on this sort of rectifier and variants. From the various converter/control topologies discussed Vienna rectifier with constant switching frequency was chosen because of the suitable rectifier for converting a generator type input, due to the following grounds.

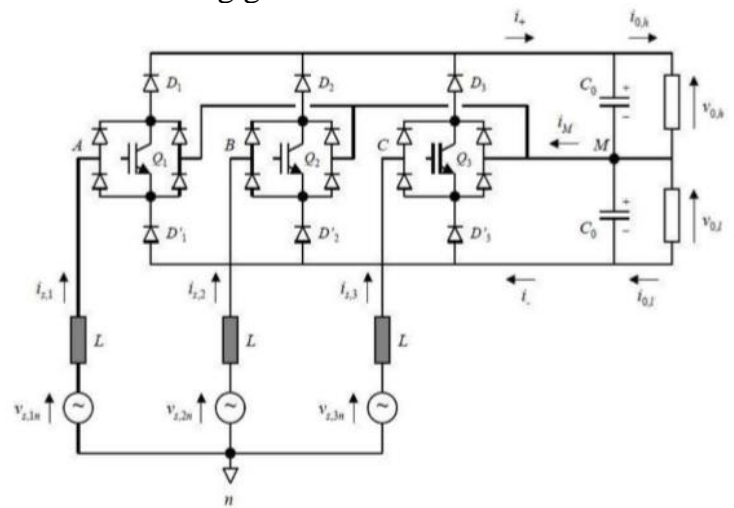

Figure1. Schematic diagram of Vienna rectifier

The Vienna rectifier offers the identical than the selection topologies The Vienna rectifier, with its threelevel output, allows any DC-DC converter to be used at the rectifier output and, with constant switching frequency control, no additional circuitry is required to balance the two outputs capacitors. The Vienna rectifier scheme diagram is shown in Figure1. The Vienna rectifier offers a topology of power electronics that's more powerful than the standard two-level PWM converter. The Vienna rectifier has recently been suggested because of the generator-side converter for PMSG-based WECS. The Vienna rectifier is employed because of the generator-side converter, which is mostly a two-level, six-switch converter. Considering that the Vienna rectifier could be a unidirectional converter, it cannot be used as an interface on the grid. Rather, it's possible to use a conventional six-switch or multi-level converter 


\section{B. Permanent Magnet Synchronous Generator}

Developing advanced Magnetic Materials, Power Electronics, and Computer Control Systems makes static magnet (PM) machine a motivating solution for a broad range of applications. Compared to other AC devices, the benefits of PMSM are its simple structure, high energy consumption, reliable operation, high power density, and therefore the possibility of super high-speed operation. Within the field of distributed generation, recent significant applications of static magnet synchronous machines are primarily in wind and micro turbine generation systems. An advantage of a high-speed generator is that the system size decreases almost directly in proportion to the rise in speed, which ends up during a very small unit.

Super high-speed PMSM could be a major factor in MTG single shaft system. During a static magnet generator, permanent magnets generate the force field of the rotor. Another generator type uses an electromagnet to come up with a force field during a revolving rotor. The electricity within the winding of the rotor field is fed by a slip-ring assembly, or by a brushless exciter on the identical shaft. In normal operation, they're more stable and secure and don't require additional DC supply for the excitation circuit. [a] The PMSG prevents the utilization of slip rings and is, therefore, easier and maintenancefree.[b]Higher coefficient of power and efficiency; Synchronous generators are appropriate for top capacity and are suitable for asynchronous generators that use more reactive power for top capacities and asynchronous generators which consume more reactive power are suitable for smaller capacities.

\section{Hysteresis current control}

The control of the rectifier input voltage and therefore the wave-shaping of input currents may be performed by the utilization of individual hysteresis controllers for every phase current. The generation of current reference for the UPF case is completed by multiplying the output of the voltage controller with sine waves of unit amplitude and in phase with the input voltages. While generating the control signals for the MOSFET, the dependency of the rectifier input voltage on the sign of the input current also should be taken into consideration by an inversion

The control of mains current is completed by control of the voltage difference across the inductor $L$. The control error of the present control loop i.e. the most current ripple error within the phase currents is proscribed to the twice the worth of the hysteresis band. Together with the control of mains current, it's also essential to balance the DC bus voltage across the capacitors $C 1$ and $C 2$.

The imbalance within the DC bus voltages may be caused by the loading of DC bus neutral point $M$ by a DC or by low-frequency AC.

It can be characterized by the difference in voltage across the capacitors as,

$$
V M=1 / 2(V c 1+V c 2)
$$

The balance of those partial voltages $(V c 1 ; V c 2)$ across $C 1$ and $C 2$ may be achieved by the addition of a zero sequence component to the present references by a voltage balance controller $\mathrm{F}(\mathrm{s})$.

The addition of a zero sequence component $i_{0}$ has no direct influence on the mains current shape (like the mains current amplitude and shape is about by the present controller and also the output voltage controller) but influences the duration of the switching states and hence the present IM, owing into the neutral point of the DC bus.

\section{Fuzzy logic controller}

Fuzzy logic represented organizational laws in terms of linguistics, instead of mathematical equations. Some systems are too complicated to model correctly, even with complex mathematical equations; hence traditional methods in these systems are infallible. However, the linguistic terms of formal logic provide a feasible method to explain the operational characteristics of such a system. First, the multiple calculated crisp inputs must be mapped into a fuzzy membership function, which is named this method fuzzification. Fuzzy device interference is shown in Figure 2. Fuzzy inference is that the method of using formal logic to formulate the mapping from a given input to an output. The mapping then provides a basis from which to form decisions or detect patterns.

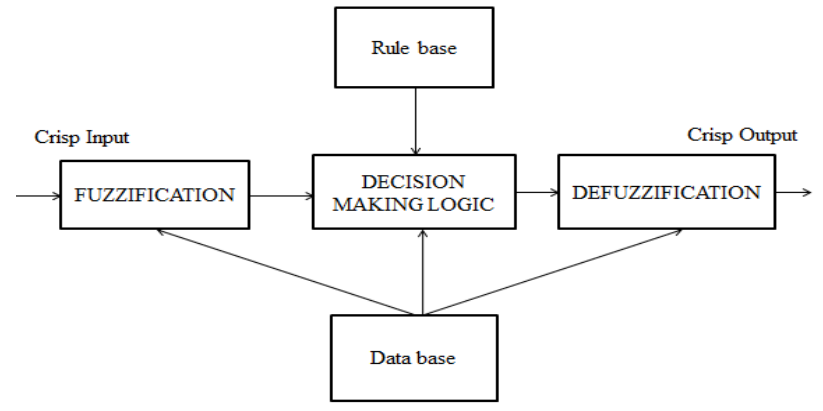

Figure 2. Fuzzy interference system

Within the formal logic Toolbox, two forms of fuzzy inference systems will be implemented: Mamdanitype and Sugeno-type. These two forms of inference systems change slightly in how outputs are calculated. Fuzzy inference systems in fields like automatic control, processing, decision analysis, expert systems, and computer vision are successfully applied. Fuzzy output variables are the output of the interference mechanism. The formal logic controller has got to transform its internal variable fuzzy output to crisp values. So that such variables are also utilized by the particular system. This conversion is named Defuzzification.

\section{IMPLEMENTATION}

Modelling may be a fundamental analytical tool, like optimization, mission, design, and control. Conversion systems for wind energy are very different from traditional generators and so complex studies must be discussed to include wind generation into the ability system. The models used for steady-state analysis are very simple, while the dynamic models for the conversion of wind energy aren't easy to develop. For various sorts of analysis associated with system dynamics, dynamic modelling is required: stability, system, and optimization. 
Table I: Value of wind turbine Parameters

\begin{tabular}{|c|c|c|}
\hline Sl. No & Parameter & Value \\
\hline 1 & Wind speed & $15(\mathrm{~m} / \mathrm{s})$ \\
\hline 2 & Blade radius & $1.4(\mathrm{~m})$ \\
\hline 3 & Air Density & 1.225 \\
\hline 4 & Number of poles & 8 \\
\hline 5 & Rated Speed & $157(\mathrm{rad} / \mathrm{sec})$ \\
\hline 6 & Armature resistance & $2.8750(\mathrm{ohm})$ \\
\hline 7 & Magnetic flux linkage & $0.07145(\mathrm{web})$ \\
\hline 8 & Stator inductance & $\begin{array}{c}0.000835 \\
(\text { Henry })\end{array}$ \\
\hline
\end{tabular}

For power systems with classical energy analysis sources, Modelling is comparatively simple because the models and process controllers are well-known and even standardized; the info is on the market.

The diagram of the proposed technique has appeared in Figure3. But within the case of turbine modelling, researchers face problems because of a lack of knowledge and lack of system structures because of strong rivalry between manufacturers of turbine systems. This ends up in matters where many researchers are modelling wind energy conversion systems in an exceedingly relatively simple way.

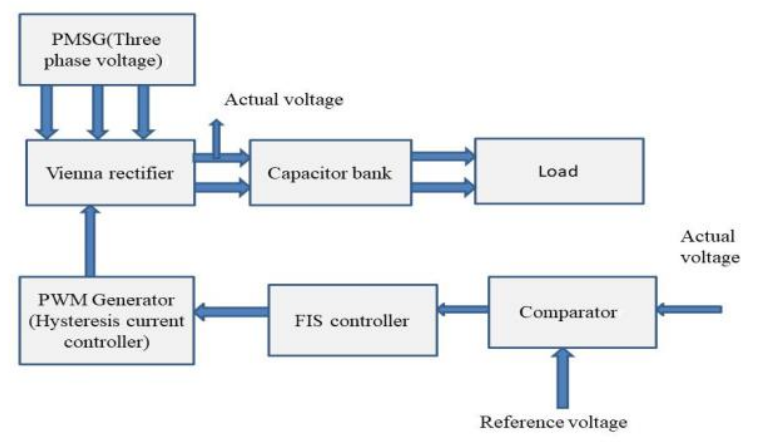

Figure 3. Block diagram of the proposed system

Nearly neglecting control systems which have a serious effect on the reliability of the analytical results. Modern generator systems for wind turbines are built mainly as systems with a horizontal axis of rotation, a wind wheel consisting of three blades, and a high-speed PMSG.

The simulation process is completed by following steps in SIMULINK/MATLAB: [1] Firstly the turbine model and PMSG model are designed. [2] So Design, modelling of the Vienna rectifier is completed. [3] Hysteresis current controller is intended and modelled for the Vienna rectifier. [4]From PMSG, the AC voltage is converted into DC voltage by using the Vienna rectifier.

\section{RESULT}

The simulation results of the Vienna rectifier Open-loop response and closed-loop system response waveform are discussed. The open-loop response of the Vienna rectifier waveform shown in figure 4. (a) And (b) when the input voltage is $100 \mathrm{~V}$ (line-line) the corresponding output voltage and currents are shown. As per the designing output voltage (150) is sort of thrice the input phase $n$ voltage. For switching sine PWM technique with a switching frequency of $50 \mathrm{KHZ}$ is employed with a modulation index $M=1.25$.

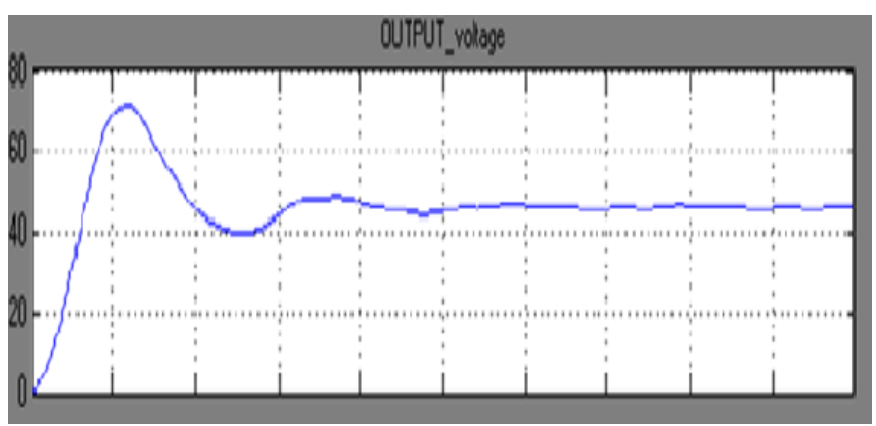

(a)

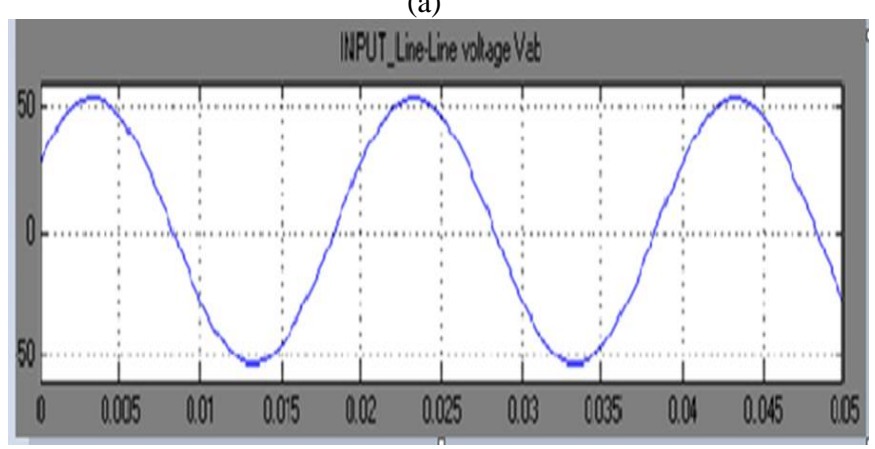

(b)

Figure 4 (a) and (b) Simulation Result of Vienna open loop for $V_{\text {in }}=55$. $5 \mathrm{~V}(1-1)$

The simulation result is shown in Figure 4(a) \& 4(b) whe $\mathrm{n}$ the input (L-L) is $55.5 \mathrm{~V}$, respectively. The simulation results is shown in Figure 5(a) \& 5(b) when input (11) is $53.5 \mathrm{~V}$, respectively.

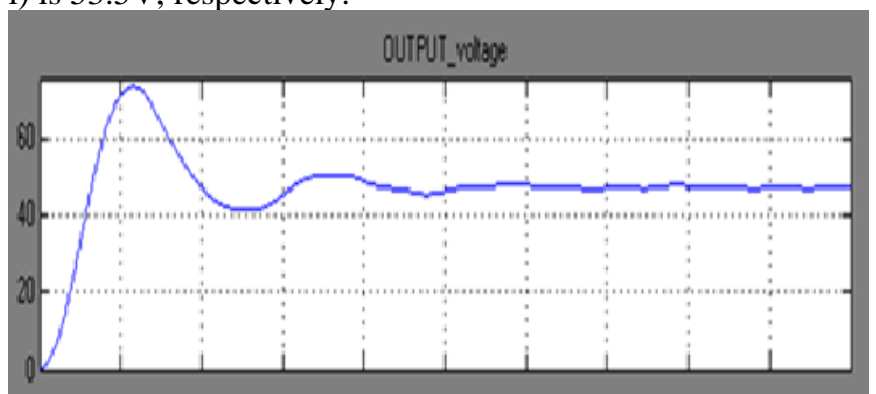

(a) 


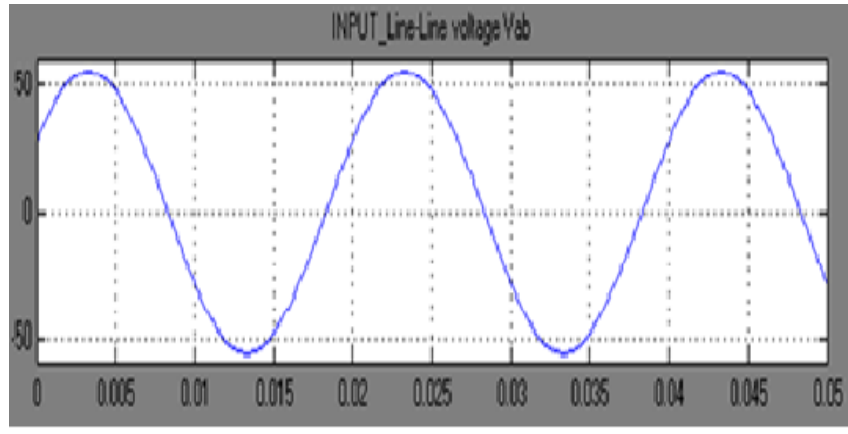

(b)

Figure5 (a) and (b) Simulation Result of Vienna open loop for $V_{i n}=53.5 \mathrm{~V}$ $(1-1)$

The efficiency of the rectifier is $85.32 \%$. Figure 5 (a) and (b) shows the closed-loop system response of the Vienna rectifier. Hysteresis based control strategies for a reduced DC bus voltage of $200 \mathrm{~V}$ tracking in $0.01 \mathrm{sec}$, after $t=0.2 \mathrm{sec}$ of simulation reference, is modified to $220 \mathrm{v}$ and its tracking that within $0.005 \mathrm{sec}$ for input line-line voltages of $100 \mathrm{~V}(\mathrm{~L}-\mathrm{L})$.

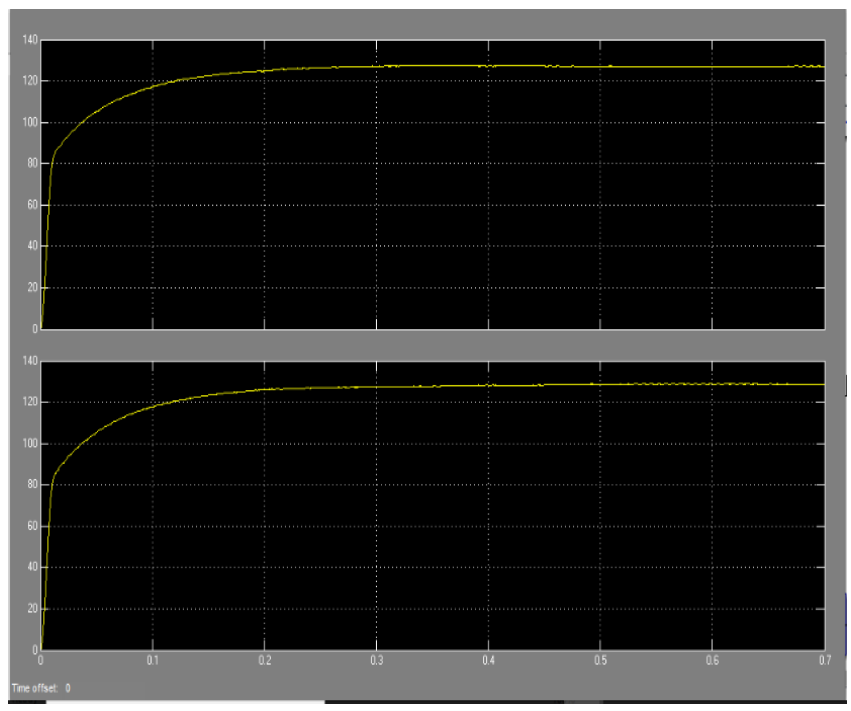

Figure6. Simulation result output voltage

The carrier frequency utilized in the hysteresis based control a frequency of fifty $\mathrm{kHz}$ is employed with a hysteresis band $h= \pm 0.001 \mathrm{~A}$. The efficiency of the complete setup is found to be $\eta=98.14 \%$ for hysteresis control.

\section{CONCLUSION}

Vienna rectifier's performance evaluation has been examined. A replacement time-variant low-frequency model of a three-phase, three switches, and three-level rectifier was developed.

Concludes the conclusions of the paper are in line with the assumption that the Vienna rectifier offers a more powerful topology of power electronics than the normal two-level PWM converter. The topology of the PMSG / Vienna rectifier is, therefore, a replacement promising design choice in which the wind energy industry should be evaluated closely. The Vienna rectifier might be far more suitable for converting an outsized source of input voltage to a DC output than a topology with a 6- switch. The hybrid Hysteresis current control and formal logic controller are accustomed which the harmonics of the source current while maintaining constant voltage to the grid furthermore.

\section{REFERENCES}

[1] S. Agrawal, V. K. Gupta, D. K. Palwalia and R. K. Somani, "Power Quality Improvement of Standalone Wind Energy Generation System for Non-Linear Load," 2018 2nd IEEE International Conference on Power Electronics, Intelligent Control and Energy Systems (ICPEICES), Delhi, India, 2018, pp. 374-379

[2] F. Amrane, A. Chiba, and B. Francois, "Suitable power control supported type-2 formal logic for wind-turbine dfig under hypo-synchronous mode fed by the multi-level converter," 2017 5th International Conference on technology - Boumerdes (ICEE-B), Boumerdes, 2017, pp. $1-6$.

[3] Dhareppagol, V. D., \&Nagendraprasad, S. (2015, October). Modeling and simulation of wecs for maximum power extraction and optimal efficiency control using squirrel cage induction generator. In 2015 IEEE Power, Communication and Information Technology Conference (PCITC) (pp. 912-917). IEEE

[4] K. Ra Jamba, B.Umamaheshwari, AndC.Chellamuthu "Steady-State Analysis of Grid - Connected Fixed-Speed Wind Turbines International Journal of Power And Energy Systems - 2005

[5] R. K. and S. K. Kottayil, "Active Power Control in Variable Speed Wind Electric Generators," 2009 International Conference on Advances in Computing, Control, and Telecommunication Technologies, Trivandrum, Kerala, 2009, pp. 717-719.

[6] V Kumar, RR Joshi, RC Bansal "Optimal Control of Matrix-Converter-Based WECS for Performance Enhancement and Efficiency Optimization" IEEE Transactions on Energy 2009.

[7] P. S. Manickam and P. Periasamy, "Tracking the utmost alternative energy Point using Neuro-Fuzzy Control with DFIG-BESS for Wind Energy System," 2018 Conference on Emerging Devices and Smart Systems (ICEDSS), Tiruchengode, 2018, pp. 16-20.

[8] A. Mesemanolis, C. Mademlis, and that i. Lioskeridis, "Copper loss minimization together with MPPT control in a very wind energy conversion system with an induction generator, "2013 International Conference on Clean electric power (ICCEP).

[9] W. Sudmee and B. Neammanee, "Performance Comparison of DC Link Voltage Controllers in Vector Controlled Boost Type PWM Converter for turbine System," 2007 7th International Conference on Power Electronics and Drive Systems, Bangkok, 2007, pp. 930936

[10] Tiwari, R., Krishnamurthy, K., Neelakandan, R.B., Padmanaban, S., and Wheeler, P.W., 2018. Neural network-based maximum power point tracking control with quadratic boost converter for PMSG - wind energy conversion system. Electronics. 